\title{
New associate editor: Prof. Ludwig Wildt
}

\section{Ludwig Wildt}

Published online: 22 January 2014

(c) Springer-Verlag Berlin Heidelberg 2014

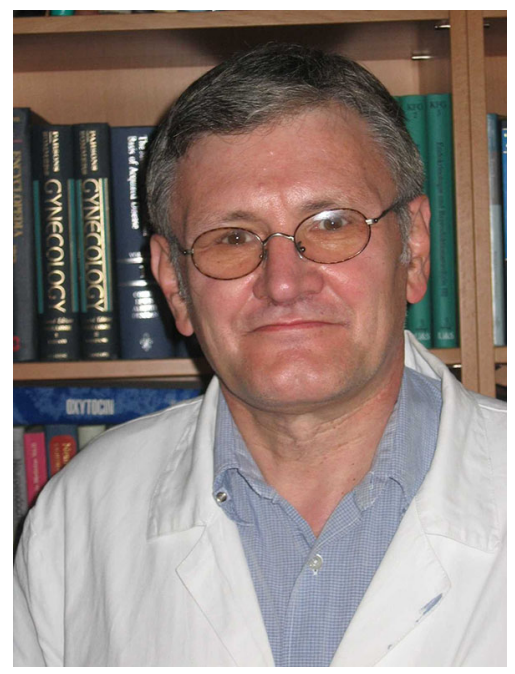

Ludwig Wildt received his medical education at the University of Bonn/Germany. He was residing at the Department of Obstetrics and Gynecology, University of Bonn. He was board certified in 1984. From 1977 to 1980 he was postdoctoral fellow of the DFG and FORD Foundation with Dr. Ernst Knobil at the Department of Physiology, University of Pittsburgh Medical School. In 1987 he became Head of the Division of Gynecologic Endocrinology and Reproductive Medicine at the Department of Obstetrics and Gynecology, University of Erlangen-Nürnberg. In 1990 he was appointed full professor. In 2003, he became Director of the University Hospital for Gynecologic Endocrinology and Reproductive Medicine at Innsbruck Medical University. He was promoted as Doctor of Medicine with summa cum laude in 1977. He received the Schöller-Junkmann Award of the German Endocrine Society in 1983 and the Award of German speaking Menopause Societies in 1994. He is a member of several scientific societies and member of the editorial board of the Journal für Reproduktionsmedizin und Endokrinologie, Gynäkologische Endokrinologie and of "Hormone molecular biology and clinical investigation". His main interest is in physiology, pathophysiology and treatment of female reproductive and endocrine disorders, in particular, hypothalamic amenorrhoea and PCO syndrome, ART and fertility protection, endometriosis, menopause and treatment of transgender patients.

\footnotetext{
L. Wildt $(\bowtie)$

Univ. Klinik für Gynäkologische Endokrinologie und Reproduktionsmedizin, Department Frauenheilkunde, Innsbruck Medical University, Anichstraße 35, 6020 Innsbruck, Austria e-mail: ludwig.wildt@i-med.ac.at
} 